\title{
Hydrological Climate-Impact Projections for the Rhine River: GCM-RCM Uncertainty and Separate Temperature and Precipitation Effects*
}

\author{
THOMAS BosSHARD ${ }^{+}$AND SVEN KOTLARSKI \\ Institute for Atmospheric and Climate Science, ETH Zurich, Zurich, Switzerland \\ MASSIMILIANO ZAPPA \\ Swiss Federal Institute for Forest, Snow and Landscape Research (WSL), Birmensdorf, Switzerland \\ CHRISTOPH SCHÄR \\ Institute for Atmospheric and Climate Science, ETH Zurich, Zurich, Switzerland
}

(Manuscript received 4 July 2012, in final form 23 October 2013)

\begin{abstract}
Climate change is expected to affect the hydrological cycle, with considerable impacts on water resources. Climate-induced changes in the hydrology of the Rhine River (Europe) are of major importance for the riparian countries, as the Rhine River is the most important European waterway, serves as a freshwater supply source, and is prone to floods and droughts. Here regional climate model data from the Ensemble-Based Predictions of Climate Changes and their Impacts (ENSEMBLES) project is used to drive the hydrological model Precipitation-Runoff-Evapotranspiration-Hydrotope (PREVAH) and to assess the impact of climate change on the hydrology in the Rhine basin. Results suggest increases in monthly mean runoff during winter and decreases in summer. At the gauge Cologne and for the period 2070-99 under the A1B scenario of the Special Report on Emissions Scenarios, projected decreases in summer vary between $-9 \%$ and $-40 \%$ depending on the climate model used, while increases in winter are in the range of $+4 \%$ to $+51 \%$. These projected changes in mean runoff are generally consistent with earlier studies, but the derived spread in the runoff projections appears to be larger. It is demonstrated that temperature effects (e.g., through altered snow processes) dominate in the Alpine tributaries, while precipitation effects dominate in the lower portion of the Rhine basin. Analyses are also presented for selected extreme runoff indices.
\end{abstract}

\section{Introduction}

There is a broad consensus that future global climate change will intensify the global hydrological cycle, although the magnitude and regional details of the projected change often remain unclear (Allen and Ingram 2002; Wild et al. 2008; Meehl et al. 2007). On regional scales, changes in the hydrological cycle can considerably

\footnotetext{
* Supplemental information related to this paper is available at the Journals Online website: http://dx.doi.org/10.1175/JHM-D-12098.s1.

+ Current affiliation: Swedish Meteorological and Hydrological Institute, Norrköping, Sweden.
}

Corresponding author address: Thomas Bosshard, Swedish Meteorological and Hydrological Institute, Folkborgsvägen 17, SE-60176, Norrköping, Sweden.

E-mail: thomas.bosshard@smhi.se deviate from the global pattern because of changes in atmospheric circulation and moisture supply, as well as because of local factors related to the topography and hydrological characteristics of the catchment considered. In snowmelt-dominated basins, for instance, the expected temperature increase will impact snow accumulation and melt dynamics and can cause important changes of the annual discharge regime (Barnett et al. 2005).

This study assesses the hydrological changes in the Rhine basin, induced by projected twenty-first-century climate changes. The Rhine basin is one of the largest river systems in central Europe. It drains into the North Sea and spans an elevation range up to $4274 \mathrm{~m}$ MSL. The Rhine River is extensively used for water supply, as a waterway, and for energy production. It is also prone to large-scale floods in winter and early spring (Disse and Engel 2001). The region of the Rhine basin is 
expected to experience climate change-induced precipitation decreases in summer and increases in winter, while temperature is projected to increase faster than the global average (Meehl et al. 2007). Given the diversity of potential climate change impacts and the importance of the Rhine, regional climate-impact studies are of high relevance for water management, navigation, and several other sectors.

Numerous studies have investigated climate-induced changes of the hydrology in the Rhine basin. Kwadijk and Middelkoop (1994) conducted a climate sensitivity study and found that within the tested scenario range, temperature changes have a smaller effect on changes in peak discharge than precipitation changes. Middelkoop et al. (2001) used monthly changes of temperature and precipitation as simulated by two general circulation models (GCMs) and applied them to a suite of hydrological models in the Rhine catchment. The results for the whole Rhine basin showed a decrease of runoff in summer and an increase of winter runoff. The authors concluded that the flood and drought risks both increase and that projected changes, despite their uncertainties, are so large that they should be considered in water management planning. Shabalova et al. (2003) were, to our knowledge, the first ones to use regional climate model (RCM) data, that is, dynamically downscaled GCM scenarios, for a hydrological impact study in the Rhine catchment. They used two methods to statistically postprocess the RCM data. The first one accounted for changes in the mean, whereas the second also accounted for changes in the variability. They found the same change pattern of mean runoff as previous studies. Furthermore, they showed that both postprocessing methods agree on an increase of runoff extremes but that the magnitude of the changes is sensitive to the choice of the postprocessing method. Kleinn et al. (2005) evaluated the performance of a hydrological model driven by RCM downscaled reanalysis data and found that runoff biases are particularly large in Alpine subbasins. Menzel et al. (2006) used a nonlinear statistical downscaling of two GCMs to study changes in runoff extremes. They found that the associated uncertainties are too large to allow for drawing any conclusions. Among other drainage basins, Graham et al. (2007) assessed the hydrological climate impacts in the Rhine basin using an ensemble of climate scenarios of the Prediction of Regional Scenarios and Uncertainties for Defining European Climate Change Risks and Effects (PRUDENCE) project (Christensen et al. 2007) that consisted of 10 RCMs driven by one single GCM. For the end of the twenty-first century, they found a decrease of monthly mean runoff in summer and autumn in the range of $-20 \%$ to $-40 \%$ and an increase in late winter and early spring in the range of +10 to
$+20 \%$ (with one outlier simulating $+40 \%$ in February). Hurkmans et al. (2010) investigated hydrological changes in the Rhine basin induced by three high-resolution regional climate scenarios assuming different emission scenarios. They found that peak flow increases over the whole twenty-first century, but drought magnitudes only increase in the second half of the twenty-first century.

Previous studies also found runoff changes in snowdominated basins to be more strongly affected by changes in temperature than in precipitation (Barnett et al. 2005). Nijssen et al. (2001) conducted a climate-impact study in macroscale river basins around the world and found that transitional catchments (i.e., catchments with average winter temperatures just below the freezing temperature) will experience a decrease of the snowmelt peak and an increase of winter and a decrease of summer runoff. They also conducted a sensitivity study and applied seasonal changes of temperature and precipitation separately to the modeled catchments. Temperature increases generally lead to a runoff decrease, but snow-dominated catchments experienced a shift in the seasonality of runoff. Precipitation increases lead to increases of runoff in all catchments, but in snow-dominated catchments, additional precipitation during winter was first stored in the snowpack and became effective in spring and summer. For the Alpine part of the Rhine basin, Graham et al. (2007) analyzed the snow cover duration as a function of mean winter temperature and precipitation and found that projected changes according to the PRUDENCE data will lead to a decrease of snow cover duration by about 75-100 days. Also, the snowmelt peak in spring was projected to occur 1 month earlier by the end of the twenty-first century. At the gauge Maxau, located along the Upper Rhine, Hurkmans et al. (2010) found the snowmelt season to start about 6-8 weeks earlier in the second half of the twenty-first century.

Recently, the Rheinblick2050 project (Görgen et al. 2010) compiled a database of hydrological climate-runoff projections based on studies of the riparian countries of the Rhine basin, carried out by various research institutions. A common simulation framework facilitated the comparison among the projections. Most of the hydrological climate-runoff projections were driven by RCM data provided by the Ensemble-Based Predictions of Climate Changes and their Impacts (ENSEMBLES) project (van der Linden and Mitchell 2009).

The present study complements the results of Rheinblick 2050 by assessing climate-induced changes in the hydrology of the Rhine River down to Cologne for the two scenario periods (SCE) 2021-50 and 2070-99 compared to the control period (CTL) 1979-2008. We use an ensemble of regional climate model projections from the ENSEMBLES project, an improved version of 
the delta change approach (Gleick 1986; Bosshard et al. 2011), and the hydrological model Precipitation-RunoffEvapotranspiration-Hydrotope (PREVAH), which has been extensively evaluated in the Alpine area (Gurtz et al. 1999; Zappa and Gurtz 2003; Viviroli et al. 2009). We also quantitatively assess the contributions of temperature and precipitation changes to the projected changes in runoff.

The paper is organized as follows: section 2 presents the study region and the data, section 3 introduces the methods of the hydrological impact modeling study, followed by section 4 presenting the results. In section 5, we summarize the results and draw conclusions.

\section{Study region and data}

\section{a. Study region}

The study region encompasses the whole Rhine catchment down to the gauge Cologne (see Fig. 1) with a total basin area of $144231 \mathrm{~km}^{2}$. The catchment covers elevations ranging from $35 \mathrm{~m}$ MSL at Cologne in the north to $4274 \mathrm{~m}$ MSL at the Finsteraarhorn located in the Alpine region in the south. Major tributaries are the Neckar, Main, and Moselle Rivers. Downstream of Basel (close to Rheinfelden), the Rhine is heavily used as a waterway. The population in the whole catchment amounts to about 50 million (Disse and Engel 2001).

\section{b. Data}

For the setup of the hydrological model in the subbasins downstream of Rheinfelden, we used soil and land use data from the European Soil Database (ESDB; version 2.0, $1 \times 1 \mathrm{~km}^{2}$ ) (King et al. 1994; Wösten et al. 1999) and a high-resolution digital elevation model (DEM) with a resolution of $75 \times 75 \mathrm{~m}^{2}$ provided by the International Commission for the Hydrology of the Rhine Basin (CHR). For the Alpine and High Rhine area upstream of Rheinfelden, we used the hydrological model setup by Verbunt et al. (2006; see section 3a).

Daily meteorological station data to force the hydrological model were provided by MeteoSwiss (Switzerland); the German Weather Service (Germany); Météo-France (France); the Federal Ministry of Agriculture, Forestry, Environment and Water Management (Austria); and the European Climate Assessment and Dataset Project (Luxembourg). Figure 1 shows the locations of the precipitation stations. For Germany, a new extensive precipitation dataset compiled by the German Weather Service was used (see Zolina et al. 2008). Since temperature is spatially less variable than precipitation, we used the gridded temperature dataset of the ENSEMBLES project (E-OBS; Haylock et al. 2008) instead of station data for

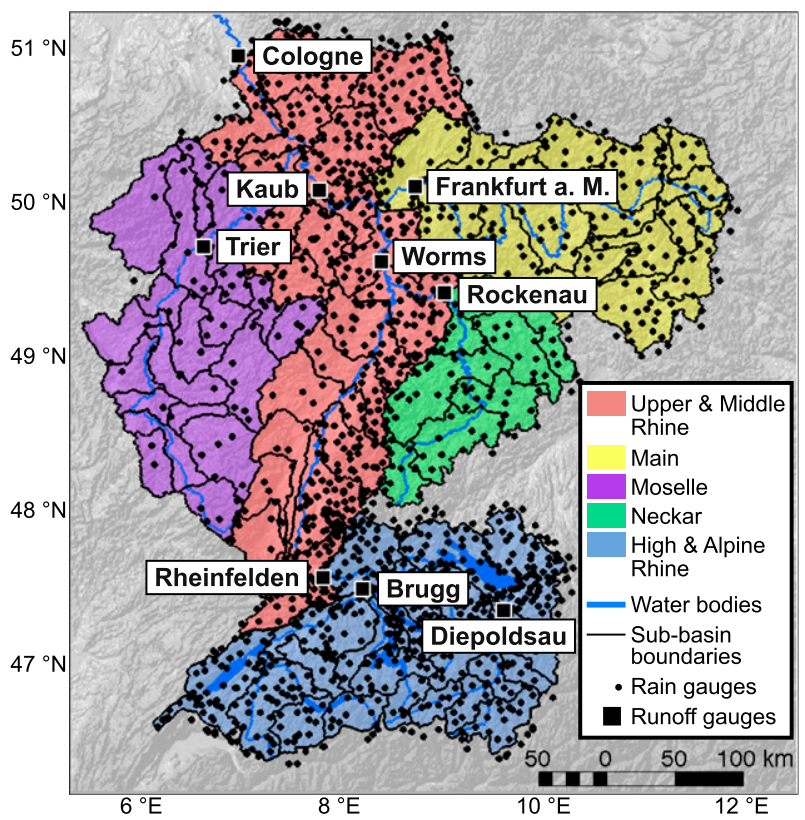

FIG. 1. Map of the Rhine basin down to Cologne indicating PREVAH subbasins and the location of precipitation and runoff gauges.

the region downstream of Rheinfelden, while for the Alpine and High Rhine upstream of Rheinfelden, we used station data. All meteorological datasets cover the whole CTL period 1979-2008. Daily runoff data for calibration and validation were provided by the responsible national and federal state agencies of the riparian countries.

As climate model data, we used output data from 10 climate modeling chains provided by the ENSEMBLES project (van der Linden and Mitchell 2009). Each modeling chain consists of a GCM, which is dynamically downscaled by an RCM (GCM-RCM). The ensemble encompasses a total of five GCMs and eight RCMs (see Table 1). Déqué et al. (2012) showed that within the ENSEMBLES GCM-RCMs, both the GCMs and the RCMs contribute substantially to the uncertainty in projected seasonal changes of temperature and precipitation. An uncertainty analysis, therefore, should include various GCMs and RCMs. Note that HadCM3Q3 is a lowsensitivity version of HadCM3Q0. Thus, these two GCMs are not independent but share similar model structures (Murphy et al. 2007). The 10 GCM-RCMs assume the A1B emission scenario, cover at least the period 19612099, and have a horizontal resolution of about $25 \mathrm{~km}$.

\section{Methods}

\section{a. Hydrological model}

In this study, we used the hydrological model PREVAH that has been widely applied for hydrological 
TABLE 1. List of the employed climate model chains from the ENSEMBLES project. In the text, we only use the GCM and RCM for reference to a specific modeling chain.

\begin{tabular}{|c|c|c|}
\hline Institution & GCM & $\mathrm{RCM}$ \\
\hline Danish Meteorological Institute & ECHAM5 & HIRHAM \\
\hline $\begin{array}{l}\text { International Centre for } \\
\text { Theoretical Physics }\end{array}$ & ECHAM5 & Regional Climate Model (RegCM) \\
\hline $\begin{array}{l}\text { Royal Netherlands Meteorological } \\
\text { Institute }\end{array}$ & ECHAM5 & Regional Atmospheric Climate Model (RACMO) \\
\hline $\begin{array}{l}\text { Max-Planck Institute } \\
\text { for Meteorology }\end{array}$ & ECHAM5 & Regional Model (REMO) \\
\hline $\begin{array}{l}\text { Swedish Meteorological and } \\
\text { Hydrological Institute (SMHI) }\end{array}$ & ECHAM5 & Rossby Center Regional Atmospheric Model (RCA) \\
\hline ETH Zurich & $\begin{array}{l}\text { Hadley Centre Coupled Model, } \\
\text { version 3, Q0 (HadCM3Q0) }\end{array}$ & Community Land Model (CLM) \\
\hline Met Office Hadley Center & HadCM3Q0 & $\begin{array}{l}\text { Hadley Centre Regional Climate Model, } \\
\text { version 3, Q0 (HadRM3Q0) }\end{array}$ \\
\hline SMHI & HadCM3Q3 & $\mathrm{RCA}$ \\
\hline $\begin{array}{l}\text { Centre National de Recherches } \\
\text { Météorologiques }\end{array}$ & $\begin{array}{l}\text { Action de Recherche Petite } \\
\text { Échelle Grande Échelle (ARPEGE) }\end{array}$ & $\begin{array}{l}\text { Aire Limitée Adaptation Dynamique } \\
\text { Développement International (ALADIN) }\end{array}$ \\
\hline SMHI & Bergen Climate Model (BCM) & RCA \\
\hline
\end{tabular}

studies in Switzerland (see, e.g., Gurtz et al. 1999; Zappa et al. 2003; Verbunt et al. 2007; Jaun et al. 2008; Rotach et al. 2009; Zappa et al. 2011). PREVAH is a semidistributed conceptual model based on hydrological response units (HRUs). In our setup, it requires daily meteorological input data of precipitation, temperature, sunshine duration, relative humidity, and wind speed. The meteorological input data were spatially interpolated to the PREVAH model grid using detrended inverse distance weighting (temperature) and inverse distance weighting (other variables). The runoff generation module contains an upper water storage that is filled by infiltration and emptied by direct runoff, interflow, and percolation to the lower subsurface storage. The lower subsurface storage produces base flow. All runoff generation processes are governed by storage time constants (Zappa and Gurtz 2003). PREVAH also includes snow and glacier modules. Precipitation separation into a snow and a rain fraction is done via a threshold temperature and a linear transition range around that threshold, and melt processes are parameterized by an extended degree-day approach including an adjustment for incoming radiation [see Eqs. (1) and (4) in Zappa et al. (2003)]. Potential evapotranspiration is estimated by the Penman-Monteith equation (Penman 1956) from which actual evapotranspiration is derived dependent on minimal stomatal resistances for the various vegetation classes and present soil moisture (Gurtz et al. 1999). Radiation is parameterized via sunshine duration according to Schulla (1997) and corrected for exposure, slope, and albedo. A precipitation adjustment factor is used to correct for precipitation gauge undercatch (Viviroli et al. 2009). The routing of channel runoff is represented by a storage-translation model that does not include the effect of spillover during flood events. PREVAH uses a basic spatial grid on which the information about elevation, soil type, soil depth, and land use for the definition of the HRUs is aggregated. We used different setups for the High-Alpine Rhine area and the rest of the basin. For the former, we used the setup of Verbunt et al. (2006) with a $500 \times 500 \mathrm{~m}^{2}$ spatial resolution. For the latter, we used a $75 \times 75 \mathrm{~m}^{2}$ DEM and $1 \times 1 \mathrm{~km}^{2}$ gridded data of soil type, soil depth, and land use to set up PREVAH with a basic spatial resolution of $400 \times 400 \mathrm{~m}^{2}$. We calibrated the model in the 6-yr period 1985-90 and validated it in the remaining 24 years of the CTL period 1979-2008. A total of 14 parameters were calibrated for each subbasin separately, using daily runoff data of 76 gauges. The calibration algorithm Model-Independent Parameter Estimation and Uncertainty Analysis (PEST; Doherty et al. 2005) was implemented to estimate an optimal parameter set. We weighted the sum of the squares of the differences between modeled and observed daily runoff values with 0.55 and the sum of the squares between the observed and modeled mean annual cycle estimated by a 31-day moving average (MA) with 0.45 .

\section{b. Statistical postprocessing of climate model data and coupling with PREVAH}

We used the delta change approach to transfer the climate model results to the hydrological model PREVAH. In this statistical postprocessing method, observed meteorological data are scaled according to a climate change signal. The delta change approach, although having the 
well-known caveat of neglecting changes in variability, is widely used in hydrological climate-impact studies (Gleick 1986; Arnell 1992; Lenderink et al. 2007).

Here we only briefly describe the method and refer to Bosshard et al. (2011) for more details. The delta change postprocessing was applied to daily values of temperature $(T)$ and precipitation $(P)$ data only. For the other meteorological variables required by PREVAH, we used the unscaled observed time series. Following Bosshard et al. (2011), we first interpolated the RCM data to the observational station sites using inverse distance weighting. At each site $i$ and for every $\operatorname{RCM} j$, we estimated the mean annual cycle $\bar{X}(d)$ in the CTL and SCE period by use of a spectral filter and derived the climate change signal $\Delta X$ according to

$$
\Delta T_{i, j}(d)=\overline{T_{i, j}^{\mathrm{SCE}}}(d)-\overline{T_{i, j}^{\mathrm{CTL}}}(d)
$$

and

$$
\Delta P_{i, j}(d)=\frac{\overline{P_{i, j}^{\mathrm{SCE}}}(d)}{\overline{P_{i, j}^{\mathrm{CTL}}}(d)},
$$

where $d$ stands for a day in the annual cycle and the superscripts indicate the period (either CTL or SCE). The observed time series at the site were then scaled according to

$$
T_{i, j}^{\prime, \mathrm{SCE}}(y, d)=T_{i, \mathrm{obs}}^{\mathrm{CTL}}(y, d)+\Delta T_{i, j}(d)
$$

and

$$
P_{i, j}^{\prime \mathrm{SCE}}(y, d)=P_{i, \mathrm{obs}}^{\mathrm{CTL}}(y, d) \Delta P_{i, j}(d) .
$$

The variable $y$ denotes the years in the CTL or SCE period and observed time series are indicated by the subscript obs.

A spectral filter was applied in order to represent the annual cycle of the climate change signal with daily resolution and to reduce the effect of natural variability. Bosshard et al. (2011) found that the commonly used averaging on a monthly basis produces artificial peaks in the annual cycle of the climate change signal. The spectral filter effectively removes such peaks.

\section{c. Separating temperature and precipitation effects}

A set of four simulations was conducted, in which all four possible combinations of unscaled or scaled temperature and precipitation data were tested:

- CTL: no scaling applied to both temperature and precipitation;
- $T$ : scaling of temperature only [Eq. (3)], precipitation remains unscaled;

- $P$ : scaling of precipitation only [Eq. (4)], temperature remains unscaled; and

- TP: scaling of temperature [Eq. (3)] and precipitation [Eq. (4)].

Each simulation resulted in a 30-yr time series of simulated daily runoff. The mean annual cycles of the four runoff time series are denoted by $Q_{\mathrm{AC}}^{\mathrm{CTL}}(d), Q_{\mathrm{AC}}^{T}(d)$, $Q_{\mathrm{AC}}^{P}(d)$, and $Q_{\mathrm{AC}}^{\mathrm{TP}}(d)$ with $d$ being the day in the annual cycle. For every day in the annual cycle, the decomposition of the total sum of squares as described in the analysis of variance theory (ANOVA; von Storch and Zwiers 1999; Bosshard et al. 2013) was applied. According to the ANOVA theory, the temperature and precipitation effect is given by $\eta_{T}^{2}(d)$ and $\eta_{P}^{2}(d)$, respectively, which quantify the sum of the squares that is explained by the particular effect in relation to the total sum of squares. Averaging over the 365 days in the annual cycle results in a mean temperature and precipitation effect $\overline{\eta_{T}^{2}}$ and $\overline{\eta_{P}^{2}}$. A value of 0 (1) indicates that the particular effect explains $0 \%(100 \%)$ of the variance (i.e., total sum of squares) in the target variable $Q_{\text {AC }}(d)$ as an average over the whole annual cycle.

\section{Results}

\section{a. Validation}

For model validation, we only show the validation results for selected gauges along the Rhine River and its major tributaries (see Fig. 1). Note that we use the term gauge both for the runoff measurement point and for the gauging point in PREVAH. Figure 2 presents the validation of the simulated mean annual runoff cycle. The runoff regime gradually changes from nival at Diepoldsau with a peak of mean runoff in summer to pluvial at Cologne with a peak in early spring. The model slightly underestimates mean runoff in spring and summer. In autumn, the model shows a systematic positive bias. A comparison with validation results of previous studies shows that the large relative biases of PREVAH during short periods in the year are within the range of other modeling studies in the Rhine basin (Shabalova et al. 2003; Kleinn et al. 2005; Lenderink et al. 2007). The volume error for the mean annual runoff at Cologne amounts to $0.8 \%$ in the calibration and to $1.0 \%$ in the validation period. The systematic bias in autumn is likely associated with inaccuracies in the seasonal evolution of terrestrial water storage. It could be explained by an overestimation of soil moisture storage or an underestimation of evapotranspiration. At the gauge Diepoldsau, winter runoff is strongly underestimated. This is at least partly due to the 

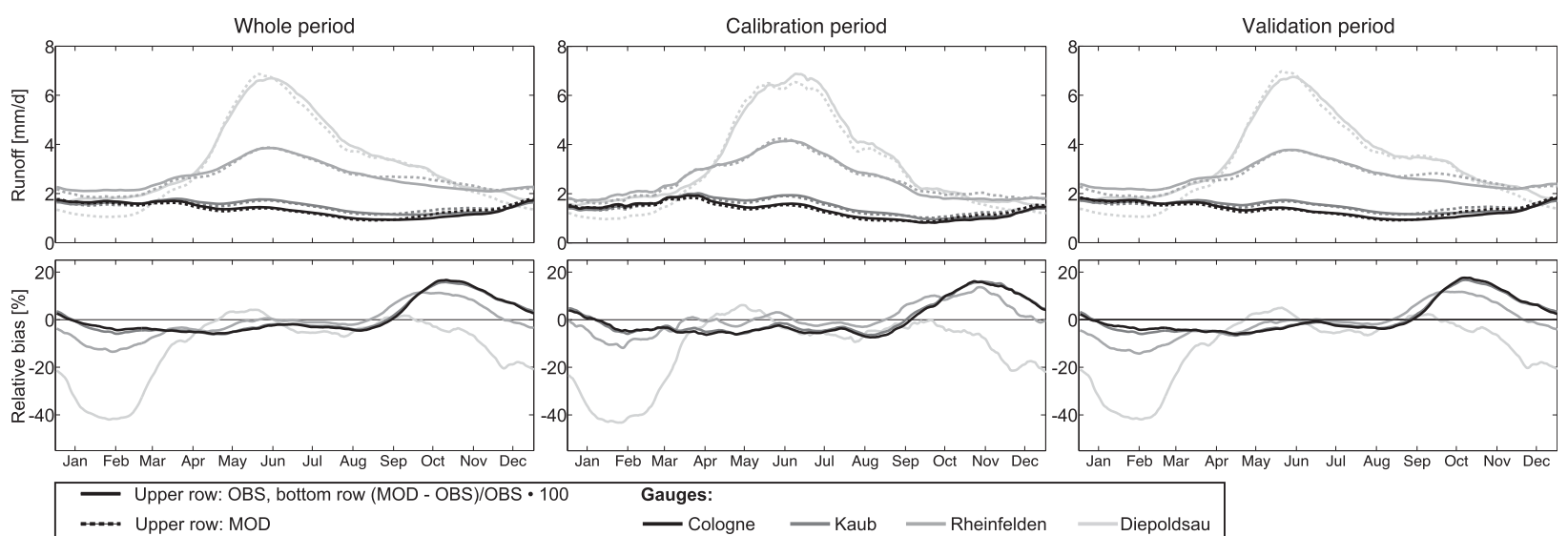

Gauges:

Cologne Kaub $=$ Rheinfelden

Diepoldsau

FIG. 2. (top) Annual cycle of observed (OBS) and modeled (MOD) runoff at selected gauges along the Rhine. (bottom) Relative bias of modeled vs observed runoff. Mean annual cycle for (left) the whole CTL period, (middle) the calibration period, and (right) the validation period.

influence of hydropower production that artificially increases the low runoff in winter. PREVAH does not include a hydropower module and therefore fails to capture the anthropogenic influence on winter low flow. Hence, estimated relative changes of low flow indices at Diepoldsau have to be interpreted with caution.

The validation using the Nash-Sutcliffe efficiency (NSE; Nash and Sutcliffe 1970) shows increasing performance when moving downstream (i.e., with an increasing catchment area; Fig. 3). The NSE value in the validation period is generally lower than in the calibration period. The difference decreases with the increasing upstream area of the gauge. Also, the spread of yearly NSE values decreases when moving downstream. The smaller the spread, the less sensitive the model performance is to the interannual variations in the CTL period.

\section{b. Spatial pattern of seasonal changes}

Here we show the spatial patterns of seasonal changes for 6 out of 10 impact modeling chains only (Fig. 4). These 6 modeling chains are driven by the 5 different GCMs used in the GCM-RCM ensemble. ECHAM5HIRHAM is included as well because it shows different characteristics than the other ECHAM5-RCMs. We show results for changes in the two hydrological model input variables temperature $(T)$ and precipitation $(P)$, as well as for changes in the two output variables evapotranspiration $(E)$ and runoff $(R)$ for summer and winter of the later SCE period 2070-99. A complete suite of results for the whole model ensemble, both SCE periods and all seasons is compiled in the supplementary material.

\section{1) TEMPERATURE}

All GCM-RCM model chains agree on a temperature increase in both seasons. The magnitude of the increase though differs within the ensemble. In winter, the ensemble range is smaller and the HadCM3Q0 and ECHAM5-driven chains roughly agree on the magnitude. HadCM3Q3-RCA, which uses the low-sensitivity run of the HadCM3Qx GCM runs, projects the strongest increase of winter temperature in our ensemble. On a global scale rather than our regional scale, a low sensitivity means that the model projects lower temperature increases for a doubling of $\mathrm{CO}_{2}$ than the other HadCM3Qx versions. ARPEGE-ALADIN shows the weakest temperature increase in the ensemble.

In summer, the HadCM3Q0-driven model chains as well as ARPEGE-ALADIN project a substantially stronger temperature increase than most of the ECHAM5driven chains. With ARPEGE-ALADIN projecting

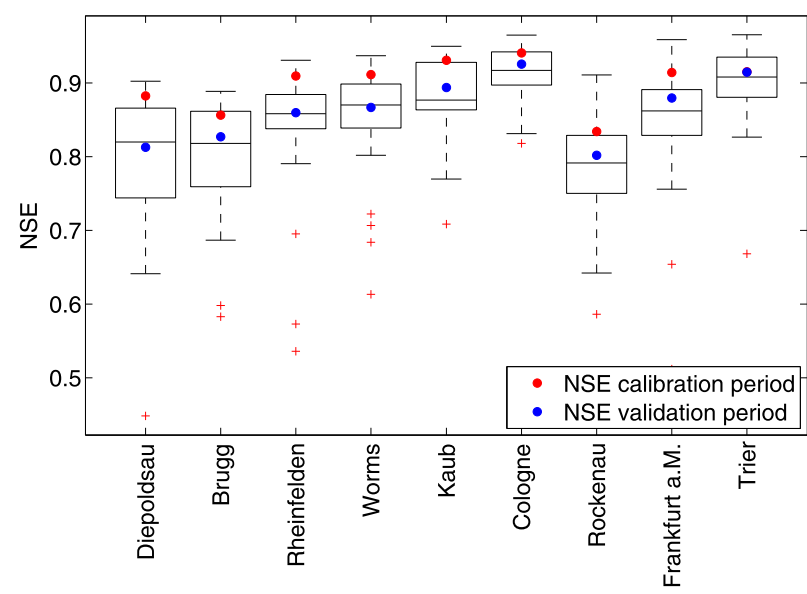

FIG. 3. NSE at gauges in the Rhine basin. Whiskers indicate the range of NSE values of the individual years in the whole CTL period. Red crosses indicate outliers. Red and blue circles show the NSE for the calibration and validation period, respectively. 
Seasonal changes, SCE: 2070-2099, CTL: 1979-2008

$\mathbf{T}$
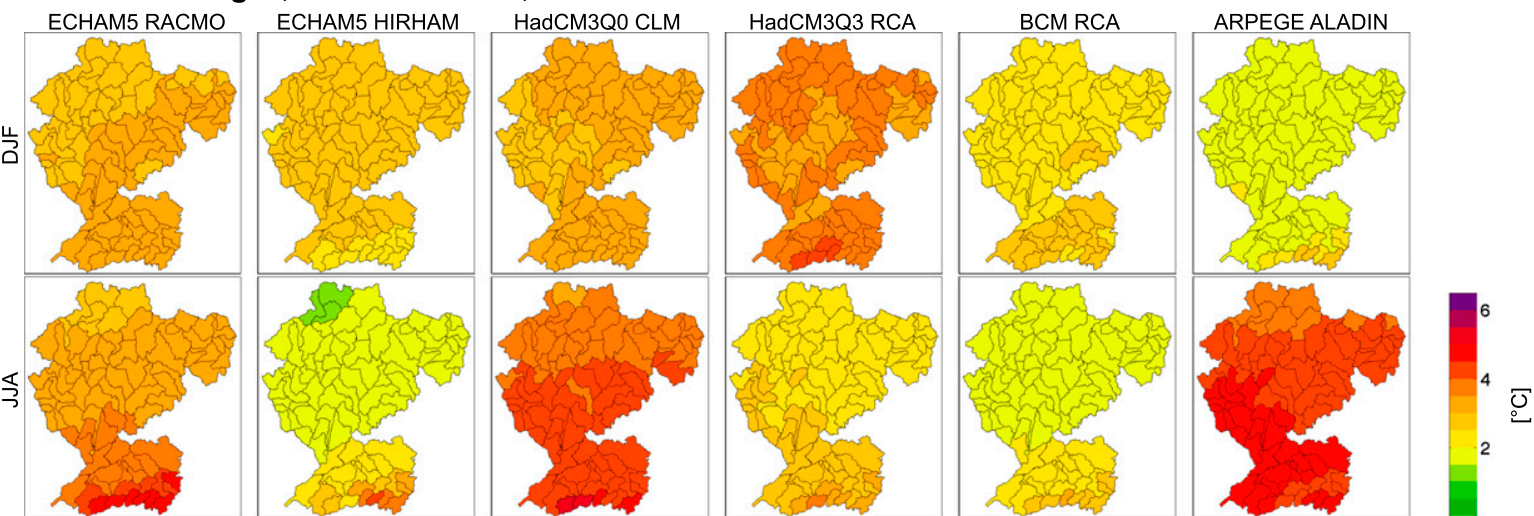

$\mathbf{P}$
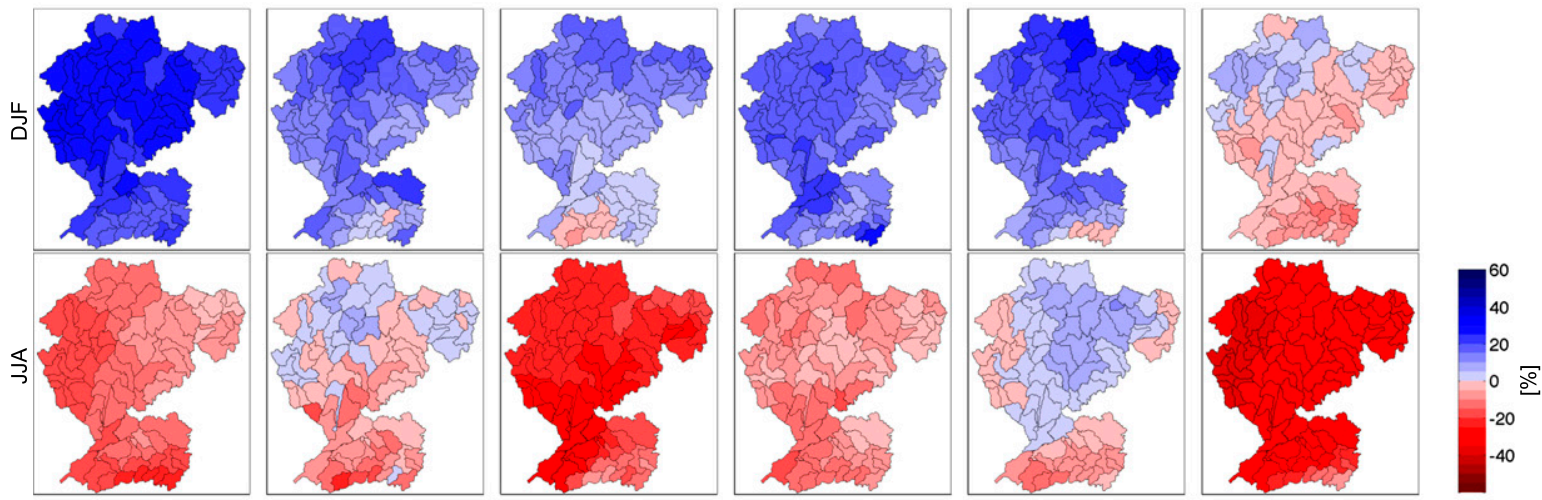

$\mathbf{E}$
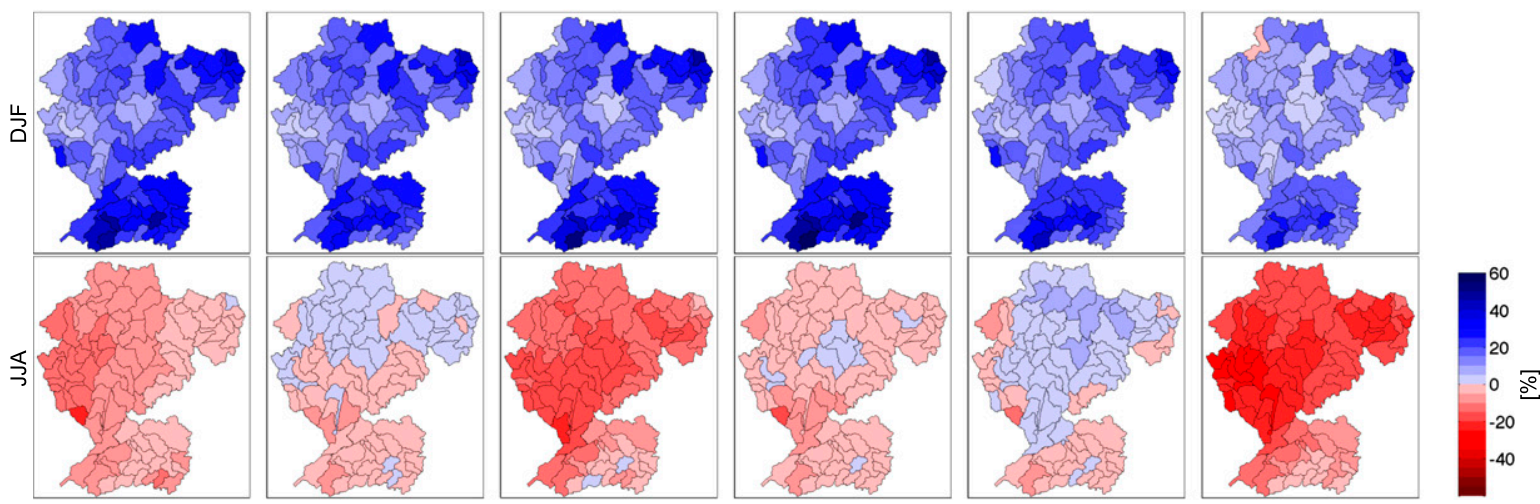

$\mathbf{R}$
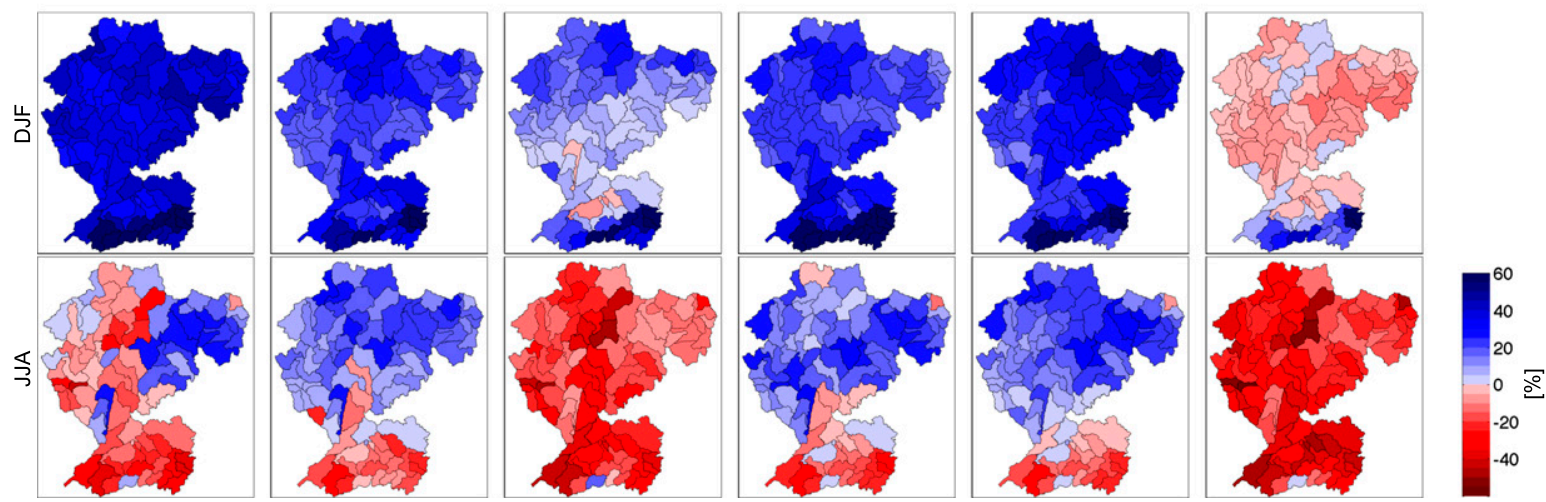

FIG. 4. Change in winter (DJF) and summer (JJA): (top to bottom) temperature $\left(T ;{ }^{\circ} \mathrm{C}\right)$, precipitation $(P$; \% ), evapotranspiration $(E$; $\%$ ), and runoff ( $R$; \%) in the subbasins for the SCE period 2070-99 vs CTL period 1979-2008 as projected by (left to right) six GCM-RCM modeling chains that span the whole ensemble range. For a given variable, the top row is for DJF and the bottom row is for JJA. 
a low temperature increase in winter, this model chain thus has the largest amplitude in the annual cycle of temperature changes. BCM-RCA, HadCM3Q3-RCA, and ECHAM5-HIRHAM are at the lower bound of the projected temperature increase. In summer, all model chains exhibit a north-south gradient in the temperature change. This gradient is probably connected to both the continental-scale pattern of warming (stronger summer warming in southern Europe) and an amplified warming at high elevations (Kotlarski et al. 2012).

\section{2) Precipitation}

In the projections of seasonal precipitation changes for winter, all model chains except for ARPEGE-ALADIN agree on an increase in $P$ for almost the whole study region apart from some high Alpine catchments that probably inherit the negative $P$ change signal from the southern Alpine region. The HadCM3Q0-driven model chains have a similar $P$ change pattern, whereas among the ECHAM5-driven model chains, substantial differences in the spatial pattern of precipitation changes occur (see supplementary material). ECHAM5-HIRHAM projects smaller increases of $P$ than the rest of the ECHAM5-driven model chains while ECHAM5RACMO and ECHAM5-RCA both are at the upper bound of the ECHAM5-driven ensemble. The three GCM-RCMs provided by SMHI using the RCM RCA show distinctly different patterns of changes in $P$. This provides further evidence that the driving GCM can have a strong effect on the dynamically downscaled precipitation climate change signal.

In summer, most model chains agree on a precipitation decrease. However, the spatial pattern is more heterogeneous than for temperature. ECHAM5-HIRHAM as well as BCM-RCA show slight increases of summer precipitation in parts of the catchment. These two model chains also project temperature changes at the lower end of the ensemble.

\section{3) EVAPOTRANSPIRATION}

All ensemble members simulate an increase of evapotranspiration in winter, though this increase is relative to a low reference value. The spatial patterns are very similar among the model ensemble.

In summer and in the southern part of the basin, the majority of the ensemble agrees on a decrease in $E$. Thus, although temperature increases suggest increasing potential evapotranspiration, the actual $E$ as estimated by PREVAH is moisture limited and decreases over large areas of the Rhine basin. Decreasing $E$ over parts of the Rhine basin was also found by Hurkmans et al. (2010), who employed a physically based hydrological model.

\section{4) RunOFF}

Most impact-modeling chains agree on an increase of winter runoff. The Alpine subbasins generally show larger increases than the other subbasins, despite lower precipitation increases. This is related to the temperature increase that causes more of the winter precipitation to fall as rain and to become runoff effective in winter instead of being stored in the snowpack until the melt season. Indeed, the recent study by Steger et al. (2013, see online supplementary material) showed a pronounced decrease of mean winter snowfall amounts over the Alps in most ENSEMBLES RCMs by 2100, while total precipitation mostly increases. In our ensemble, ARPEGEALADIN is the only modeling chain that projects runoff decreases in winter in a large fraction of the Rhine basin. This is consistent with its precipitation change pattern.

For summer, the spatial patterns of changes in $R$ deviate substantially between the ensemble members driven by different GCMs. The HadCM3Q0-driven chains and ARPEGE-ALADIN project large runoff decreases, consistent with the pronounced decrease of summer precipitation. The ECHAM5-driven chains also project runoff decreases in the Alpine region, along the Upper and Middle Rhine and parts of the Moselle catchment in the northwestern part of the basin. In the Main and Neckar catchments, however, the ECHAM5driven chains project runoff increases, despite decreasing precipitation in this region. This pattern can probably be explained by groundwater processes, which are of major importance, particularly in the Main catchment (CHR/KHR 1978): the ECHAM5-driven chains project larger precipitation increases in winter and spring than the HadCM3Q0-driven chains and ARPEGE-ALADIN. This additional surplus of winter and spring precipitation refills the soil water storage. The elevated soil water storage levels last until summer and cause increasing summer runoff by increased base flow. The same also applies to BCM-RCA and SMHIHadCM3Q0-RCA, accompanied by less pronounced decreases of summer precipitation than projected by the ECHAM5-driven chains.

\section{c. Changes in the annual cycle of water balance components}

At selected gauges in the Rhine basin, we show the annual cycles of the water balance quantities $P, E$, and $R$ in the CTL period (Fig. 5) and their changes for the SCE period 2070-99 with respect to CTL (Fig. 6). For results at additional gauges and the SCE period 2021-50, please see the supplementary material.

Figure 5 shows how the relevance of the water balance quantities varies within the basin and throughout the 

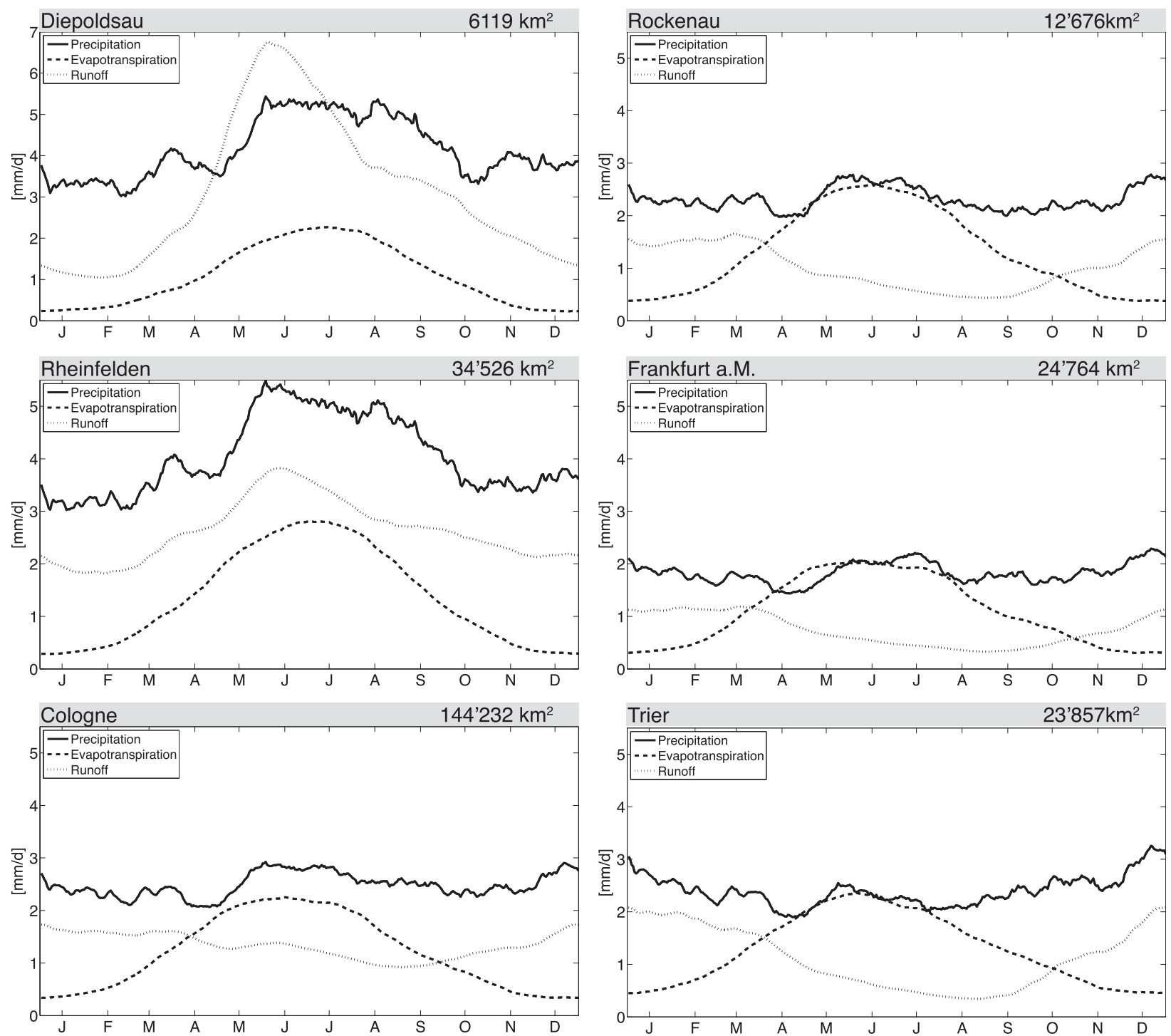

FIG. 5. Mean annual cycle of the water balance quantities precipitation (solid lines), evapotranspiration (dashed), and runoff (dotted) in the CTL period 1979-2008 for gauges along (left) the Rhine River and (right) three of its major tributaries. See Fig. 1 for gauge locations and Fig. ESM19 in the supplementary material for results at other gauges. Precipitation is estimated from observations and includes a water balance correction as derived by the hydrological model PREVAH. Evapotranspiration and runoff are estimated by PREVAH.

annual cycle. At gauges close to the Alps (Diepoldsau and Rheinfelden), $P$ and $R$ are always larger than $E$. Farther downstream and in the tributaries, $E$ almost balances $P$ in summer, which causes the summer lowflow season.

In Fig. 6, results are shown for the 10 different GCMRCM chains, and the coloring of the hydrological impact projections is grouped according to the driving GCM (red to yellow for ECHAM5, blue for HadCM3Qx, and green for others). The figures show the spatial integral over the whole area upstream of the respective gauge. For the gauges along the Rhine River (left column in
Fig. 6), the change signals resemble each other since their upstream areas partly overlap.

For precipitation, most models agree on a decrease of $P$ in summer at all gauges. The change signal varies considerably between the GCM families. At all gauges in the tributaries (right column in Fig. 6), the HadCM3Q0-driven modeling chains and ARPEGEALADIN show a more pronounced and prolonged decrease of $P$ in summer than the rest of the ensemble. This also applies to the farthermost downstream gauge at Cologne where the maximal decrease varies between $-5 \%$ and $-40 \%$. Also, there is a broad agreement 

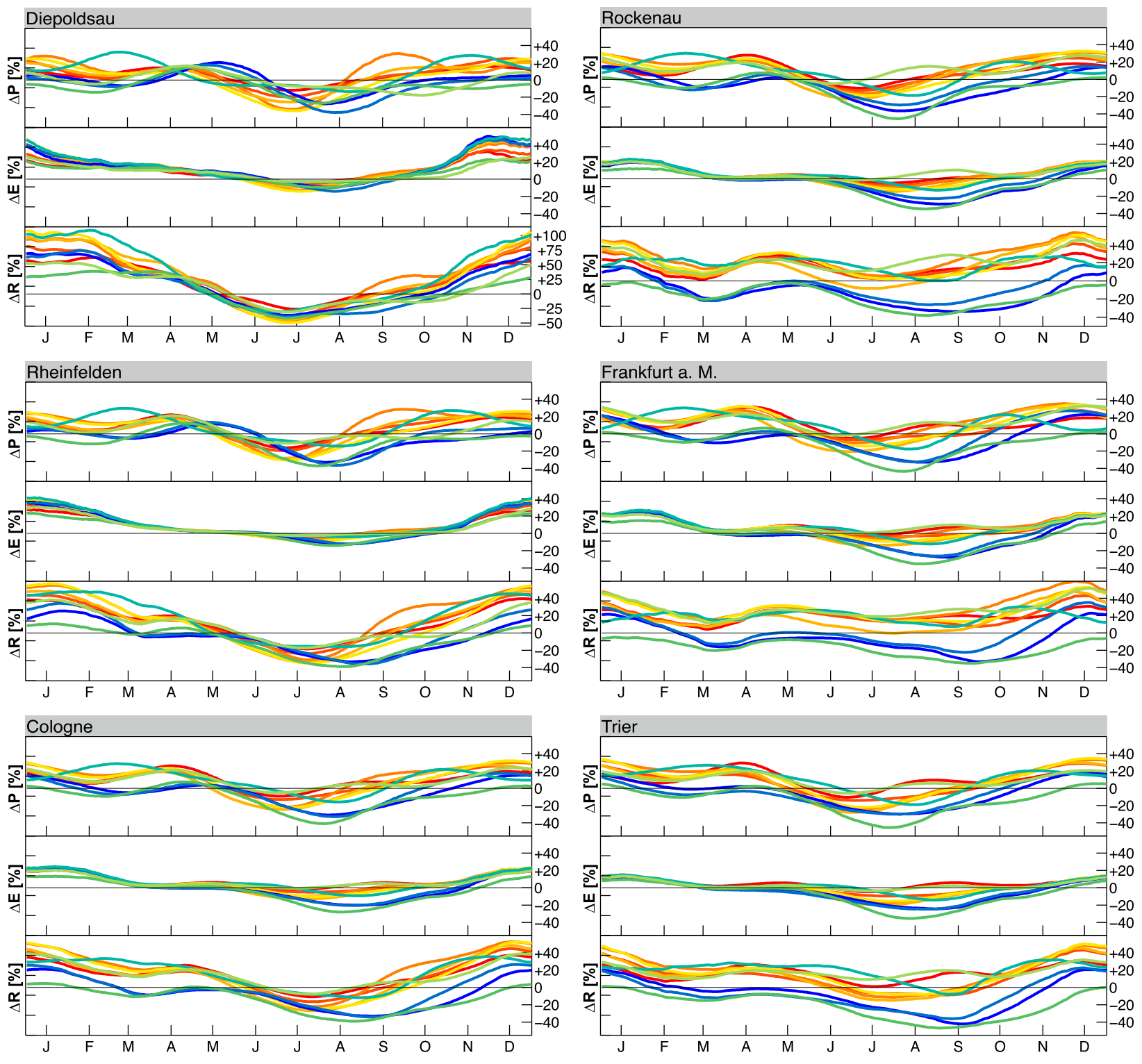

$\begin{array}{lll}\text { - ECHAM5 HIRHAM } & \text { - ECHAM5 RACMO } & \text { - ECHAM5 RCA } \\ \text { - ECHAM5 REGCM } & \text { - ECHAM5 REMO }\end{array}$

FIG. 6. Relative percent changes at each gauge location in (top to bottom) the mean annual cycle of precipitation $(\Delta P)$, evapotranspiration $(\Delta E)$, and runoff $(\Delta R)$ for gauges along (left) the Rhine River and (right) three of its major tributaries for the 10 hydrological scenarios. The gauge name is indicated in the top left corner of each panel pair. Changes are shown for SCE 2070-99 relative to the CTL period 1979-2008. Changes for the SCE 2021-50 are shown in Fig. ESM20 of the supplementary material.

among the ensemble for an increase of $P$ in the rest of the year with the largest increase generally occurring in late autumn and early winter.

For evapotranspiration, all modeling chains agree on an increase of $E$ in winter at all gauges. In summer of the second SCE period, all gauges except for Frankfurt a.M. show a decrease of $E$. In the Alpine area, the decrease is smaller than in the other areas. The impactmodeling chains showing the largest decreases of $P$
(HadCM3Q0-driven chains and ARPEGE-ALADIN) also show the largest decreases of $E$.

For runoff, $R$ is projected to increase in winter and decrease in summer at gauges along the Rhine. This is the typical pattern of change found in snow-dominated catchments (Barnett et al. 2005) and is already apparent in the SCE period 2021-50 (see supplementary material). In the tributaries, however, there is no clear tendency but the ensemble is split up into two groups. The 


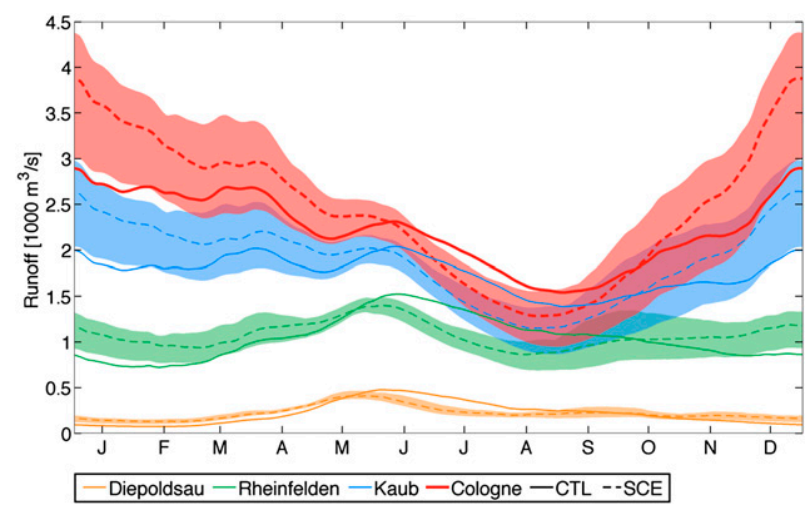

FIG. 7. Mean annual cycles of runoff at gauges (colors) along the Rhine River for the CTL period (solid lines) and SCE period 2070 99 (shaded areas). The shading indicates the range of the 10 hydrological scenarios for the SCE whereas the dashed lines show the ensemble mean.

first group consists of the ECHAM5-driven modeling chains, HadCM3Q3-RCA and BCM-RCA, which generally project increases of $R$ during the whole year except for some short periods in summer and autumn. The second group, consisting of the HadCM3Q0-driven modeling chains and the ARPEGE-ALADIN, projects decreases of $R$ during most of the annual cycle except for late autumn and early winter. These modeling chains also project large decreases of $P$ in the tributaries. Along the Rhine river, the change patterns of the tributary areas are superimposed upon the Alpine pattern of decreasing and increasing $R$ in summer and winter, and consequently, the two groups mentioned above become clearer the more downstream the gauge is. The projected maximum decreases of $R$ in summer range from $-9 \%$ to $-40 \%$ and the maximal increases in winter are in the range of $+4 \%$ to $+51 \%$.

Figure 7 shows the climate-induced changes of the runoff regime along the Rhine River in absolute terms. While the relative changes of $R$ are similar for gauges along the Rhine River (see Fig. 6), they act on different regimes. At gauges in the Alpine Rhine, the summer decrease takes place in a period of high mean flows, whereas the winter increase of $R$ coincides with the period of low flows. Thus, the amplitude of the mean annual cycle of $R$ decreases. The opposite is true for gauges farther downstream, where the summer decrease and winter increase coincide with the low-flow and highflow seasons, respectively. As a consequence, the amplitude of the mean annual cycle at downstream gauges is larger in the future SCE period, which might enlarge the risk for floods and droughts. Compared to the results in the Rheinblick2050 project (Görgen et al. 2010), the mean runoff values in our study, both in CTL and SCE, are higher at Kaub and Cologne. This is partly related to a different choice of the CTL period in Rheinblick2050, which was set to 1961-90. Belz et al. (2007) reported increasing trends of mean runoff values throughout the twentieth century, which is in line with the differences between the mean runoff values in our CTL and the CTL in Rheinblick2050.

\section{d. Changes of runoff indices}

Note that, because of limitations in all involved modeling systems, that is, climate models, statistical postprocessing, and hydrological model, projected changes in low and high flows are less reliable than changes in mean flow. For instance, the implemented delta change postprocessing method does not account for changes in the spatiotemporal variability of $T$ and $P$. Nevertheless, we include this analysis in order to compare it to previous studies using other postprocessing methods and hydrological models. The analysis shows how the extremes would change assuming no changes in variability.

Following Görgen et al. (2010), changes in three standard runoff indices are presented in Fig. 8. For low flows, we use the $90 \%$ quantile of the flow duration curve (FDC90) and the mean of the lowest 7-day mean runoff per year in the simulation period (NM7Q). For high flows, we use the mean highest 1-day runoff per year in the simulation period (MHQ).

Regarding low-flow indices, both the FDC90 and the NM7Q increase at gauges close to the Alps (Diepoldsau and Rheinfelden). Note that, because of the underestimated low flows in winter, the relative increase is probably overestimated. For gauges farther downstream, there is no clear tendency in the SCE period 2021-50. While the HadCM3Q0-driven scenarios and ARPEGE-ALADIN project slight decreases, the rest of the ensemble shows small increases. For 2070-99, the signal of the HadCM3Q0-driven scenarios and ARPEGE-ALADIN show a more pronounced decrease.

A plausible explanation for the gradient of the changes in the low-flow indices along the river course is the changing runoff regime. At gauges close to the Alps, the low-flow season is in winter when increasing $T$ combined with increasing $P$ will lead to an increase of $R$. Farther downstream, the low flows typically occur in summer when decreasing $P$ leads to decreasing mean $R$. However, it seems that the substantial decrease of mean $R$ in summer as shown in Fig. 6 is not transferable to changes in the low-flow indices as, for example, the ECHAM5-driven modeling chains show an increase of FDC90 and NM7Q. A possible explanation might be that the extreme low flows are constrained by the groundwater level, which leads to a seasonal memory, that is, the groundwater level in summer depends on the level in the previous seasons. Indeed, in the SCE we see 

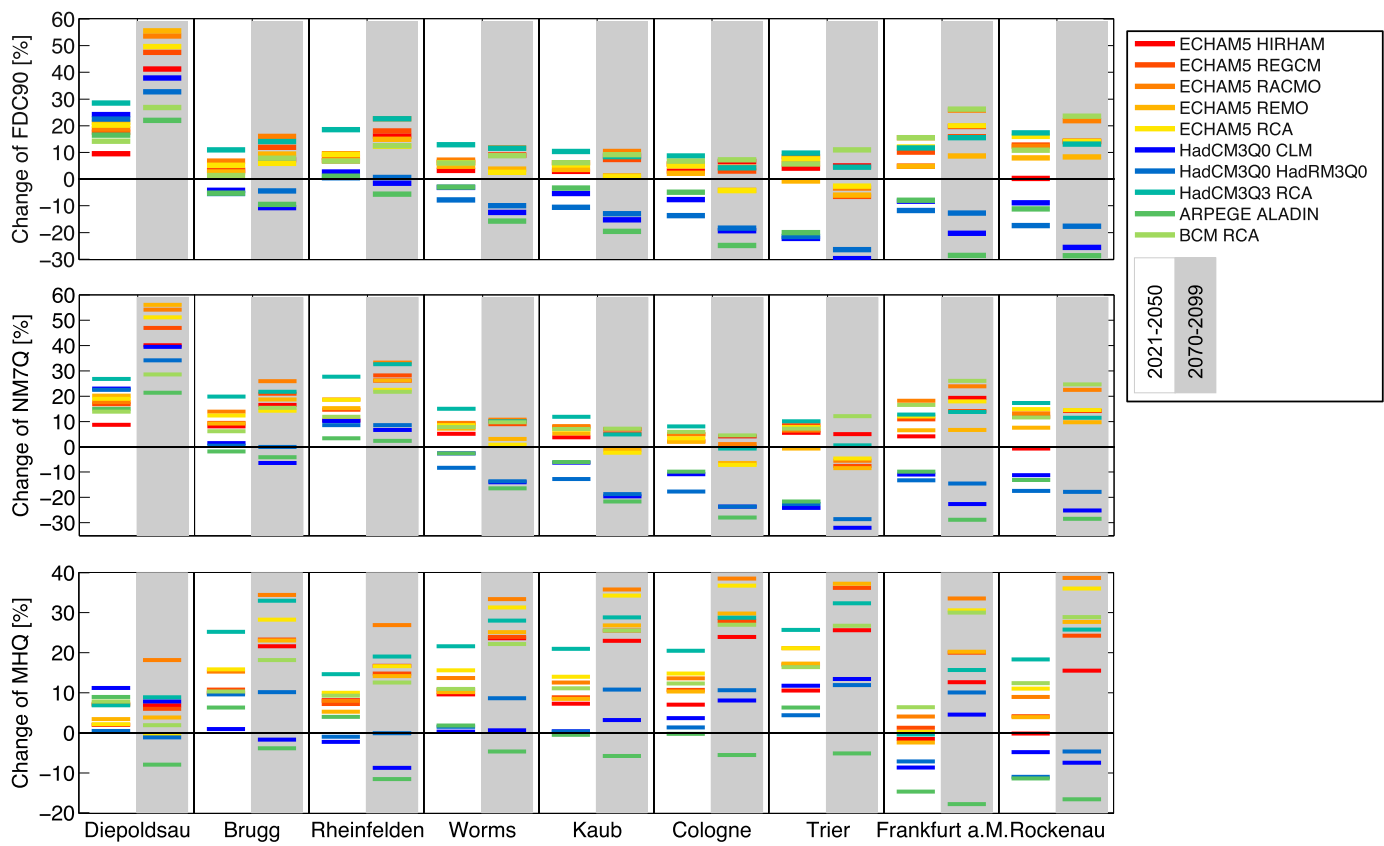

FIG. 8. Percent changes of runoff indices (top to bottom) FDC90, NM7Q, and MHQ at (left to right) selected gauges along the Rhine for the SCE periods 2021-50 (white background) and 2070-99 (gray background) for the 10 hydrological scenarios (colors).

higher water storage levels in PREVAH's lower subsurface storage reservoir in winter, spring, and subsequently in summer as well, compared to the CTL. This is related to higher precipitation amounts during winter and spring. In the ECHAM5-driven modeling chains, the increase of $P$ in winter and spring is larger than in, for example, the HadCM3Q0-driven chains, lifting the groundwater level all year round and causing increasing low flows.

At most gauges, the MHQ is projected to increase in both SCE periods, with more pronounced increases in the later period. However, the HadCM3Q0-driven scenarios as well as ARPEGE-ALADIN are generally at the lower end of the ensemble and even show slight decreases in a few cases. At Cologne, the changes range from $-7 \%$ to $+37 \%$. This is similar to the results in Görgen et al. (2010), who found changes of the MHQ at Cologne in the range of $-5 \%$ to $+25 \%$ for $2070-99$, but the upper limit of the range is considerably higher. Note that they used a bias correction for the statistical postprocessing, which allows for changes in variability, and that they also based their results on the reference period 1961-90.

The results obtained for extreme runoff indices qualitatively agree with results from previous studies for the Rhine River. Here we summarize results for the gauge Lobith about $180 \mathrm{~km}$ downstream of Cologne. Shabalova et al. (2003) estimated an increase of 20-yr runoff maxima by about $14 \%-29 \%$ for the end of the twenty-first century. Lenderink et al. (2007) found increases of $10 \%$ and $30 \%$ in 100 -yr return period discharge levels for scenarios using a bias-correction method and the delta change method, respectively. Hurkmans et al. (2010) reported increasing annual daily runoff maxima for the whole twenty-first century and te Linde et al. (2010) projected an increase of the peak discharge level of about $8 \%-17 \%$ for $2036-65$ compared to $1961-$ 95 . Because of differences in the study setup, our results cannot be compared systematically to the above-listed studies. However, our results generally agree on the sign of the changes in runoff extremes, but cover a wider range than the previous studies.

\section{e. Separate T and P effect}

Here we present an assessment of the importance of separate changes in temperature and precipitation for future runoff conditions. For simplicity, we restrict this analysis to the GCM-RCM chain HadCM3Q0-CLM, but we expect similar results for the other model chains.

Figure 9 shows the changes in the mean annual cycle of runoff and actual evapotranspiration, as projected by the separate $T$ and $P$ effect experiments as well as by the fully nonlinear simulation integrating both $T$ and $P$ effects at selected gauges along the Rhine River. Qualitatively speaking, the closer the separate effect experiments (using either the $T$ or $P$ effect) follow the nonlinear simulation, the higher the contribution of temperature or precipitation to the runoff changes. Table 2 complements 

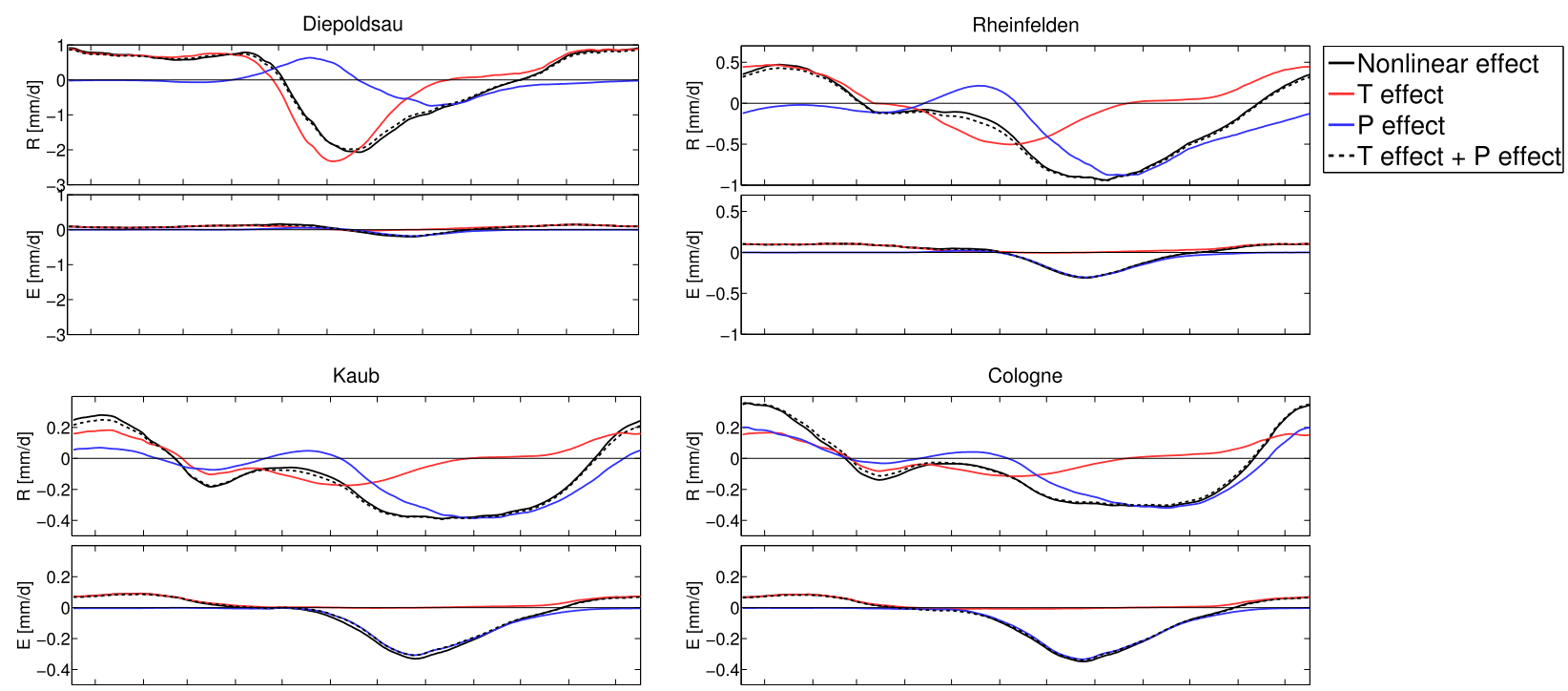

FIG. 9. Difference in mean annual cycle of routed runoff $(R)$ and evapotranspiration $(E)$ between the SCE period 2070-99 and the CTL period at four gauges along the Rhine resulting from temperature $(T)$ and precipitation $(P)$ change experiments. The full nonlinear effect of temperature and precipitation changes (TP) is shown as a black solid line. The dashed line represents the sum of the separate $T$ and $P$ results. The closer the agreement between the dashed and the solid black lines, the more additive are the $T$ and $P$ effects.

Fig. 9 by listing seasonally aggregated numbers for various water balance components.

At Diepoldsau, the changes in the annual cycle of runoff are largely determined by the $T$ effect. At Rheinfelden, the $T$ effect determines the runoff change signal in winter, while in late summer and early autumn, the $P$ effect is more relevant. At Kaub and Cologne, both the $T$ effect and the $P$ effect contribute to the increase in mean runoff during winter, while in summer, the changes in runoff are almost exclusively determined by the $P$ effect.

The experiments show further that the decrease of summer evapotranspiration reported in section $4 b(3)$ is mainly due to the $P$ effect. The small change of evapotranspiration in the $T$-effect experiment during summer can be explained by the low soil moisture in summer, effectively limiting evapotranspiration already in the CTL period. In winter, the $T$ effect governs the evapotranspiration changes.

The analysis of the individual storage terms for the entire year and the hydrological half years as presented in Table 2 show that PREVAH's internal water balance is closed on annual as well as on seasonal scales.

The sum of the $T$ and $P$ effect is indicated by the dashed line. The closer this sum follows the nonlinear simulation, the more linear (i.e., additive) the $T$ and $P$ effects are. The results show that at all evaluated gauges, the $T$ and $P$ effects are close to additivity. This is surprising since the hydrological model includes nonlinear processes that are expected to be sensitive to changes in $T$ or $P$. For instance, it includes many threshold effects (related to snowmelt or interception storage, among others) that make the runoff response, at least in principle, nonlinear. Nonlinearities due to evapotranspiration effects are visible at Kaub during summer when nonlinear evapotranspiration decreases slightly stronger than for the sum of the individual $T$ and $P$ effects. Overall, the nonlinearity in the mean runoff changes is small and justifies an additive ANOVA model for further quantification of the $T$ and $P$ effect.

Figure 10 shows the spatial pattern of the contribution of the single effects ( $T$ or $P$ ) to the changes in the mean annual cycle of the routed runoff, as quantified by an ANOVA model (see section 3c). Since the routed runoff is analyzed, the result for each gauge is not the contribution of the single effect on the runoff changes in the nearest upstream subbasin but the integrated contribution of the single effect for the whole upstream area.

The results show that the $T$ effect has a high contribution in the Alpine region. This influence is routed along the Upper and Middle Rhine almost down to Cologne. In the Neckar, Main, and Moselle catchments, however, the $P$ effect is more important than the $T$ effect. Thus, the propagated importance of the $T$ effect from the Alpine to the Middle Rhine is diminished at the confluences of the tributaries with the Rhine. At Cologne, the $P$ effect is slightly more important than the $T$ effect for changes in the mean annual cycle of runoff. The pattern in Fig. 10 suggests that the $T$ effect might largely be explained by snowmelt and accumulation processes, as the respective signal is strongest in the Alpine region and the downstream gauges, while the low-altitude tributaries are dominated by the $P$ effect. 
TABLE 2. Water balance components for the $T$ and $P$ effect experiments (CTL, no changes; $T, T$ effect; $P, P$ effect; TP, nonlinear effect) evaluated at the four gauges Diepoldsau, Rheinfelden, Kaub, and Cologne for the annual mean, the hydrological summer (May-October) and winter (November-April) half year. Variables: precipitation $(P)$, runoff $(R)$, evapotranspiration $(E)$, total storage change $(\Delta S)$, change in snow water equivalent $(\Delta \mathrm{SWE})$, change in soil moisture $(\Delta \mathrm{SM})$. The values $\Delta S, \Delta \mathrm{SWE}$, and $\Delta \mathrm{SM}$ refer to storage changes between the beginning and the end of the respective analysis period, converted to average daily values. All units are given in mm day ${ }^{-1}$.

\begin{tabular}{|c|c|c|c|c|c|c|c|c|c|c|c|c|}
\hline \multirow[b]{2}{*}{ Variable } & \multicolumn{4}{|c|}{ Annual mean } & \multicolumn{4}{|c|}{ Hydrological summer } & \multicolumn{4}{|c|}{ Hydrological winter } \\
\hline & CTL & $T$ & $P$ & $\mathrm{TP}$ & CTL & $T$ & $P$ & $\mathrm{TP}$ & CTL & $T$ & $P$ & TP \\
\hline \multicolumn{13}{|c|}{ Diepoldsau } \\
\hline$P$ & 4.1 & 4.1 & 4.0 & 4.0 & $4.7^{1}$ & 4.7 & 4.4 & 4.4 & 3.6 & 3.6 & 3.7 & 3.7 \\
\hline$R$ & 3.1 & 3.1 & 3.0 & 3.0 & 4.5 & 3.8 & 4.3 & 3.7 & 1.7 & 2.4 & 1.6 & 2.4 \\
\hline E & 1.1 & 1.2 & 1.1 & 1.1 & 1.7 & 1.7 & 1.7 & 1.7 & 0.5 & 0.6 & 0.5 & 0.6 \\
\hline Glacier melt & 0.0 & 0.1 & 0.0 & 0.1 & 0.1 & 0.3 & 0.1 & 0.3 & 0.0 & 0.0 & 0.0 & 0.0 \\
\hline$\Delta S$ & -0.0 & -0.0 & -0.0 & -0.0 & -1.4 & -0.6 & -1.5 & -0.7 & 1.5 & 0.6 & 1.6 & 0.7 \\
\hline$\Delta \mathrm{SWE}$ & 0.0 & 0.0 & 0.0 & 0.0 & -1.7 & -0.6 & -1.7 & -0.7 & 1.7 & 0.6 & 1.8 & 0.7 \\
\hline$\Delta \mathrm{SM}$ & -0.0 & -0.0 & -0.0 & -0.0 & -0.0 & -0.0 & -0.0 & -0.0 & 0.0 & 0.0 & 0.0 & 0.0 \\
\hline \multicolumn{13}{|c|}{ Rheinfelden } \\
\hline$P$ & 4.0 & 4.0 & 3.7 & 3.7 & 4.6 & 4.6 & 4.1 & 4.1 & 3.4 & 3.4 & 3.4 & 3.4 \\
\hline$R$ & 2.7 & 2.7 & 2.4 & 2.5 & 3.2 & 3.0 & 2.8 & 2.6 & 2.2 & 2.5 & 2.1 & 2.4 \\
\hline$E$ & 1.4 & 1.4 & 1.3 & 1.4 & 2.1 & 2.1 & 2.0 & 2.0 & 0.6 & 0.7 & 0.6 & 0.7 \\
\hline Glacier melt & 0.0 & 0.1 & 0.0 & 0.1 & 0.1 & 0.2 & 0.1 & 0.2 & 0.0 & 0.0 & 0.0 & 0.0 \\
\hline$\Delta S$ & 0.0 & -0.0 & 0.0 & -0.0 & -0.6 & -0.2 & -0.7 & -0.3 & 0.6 & 0.2 & 0.7 & 0.3 \\
\hline$\Delta \mathrm{SWE}$ & 0.0 & -0.0 & 0.0 & -0.0 & -0.6 & -0.2 & -0.6 & -0.2 & 0.6 & 0.2 & 0.6 & 0.2 \\
\hline$\Delta \mathrm{SM}$ & -0.0 & -0.0 & -0.0 & -0.0 & -0.0 & -0.0 & -0.0 & -0.0 & 0.0 & 0.0 & 0.0 & 0.0 \\
\hline \multicolumn{13}{|c|}{ Kaub } \\
\hline$P$ & 2.6 & 2.6 & 2.4 & 2.4 & 2.7 & 2.7 & 2.3 & 2.3 & 2.4 & 2.4 & 2.5 & 2.5 \\
\hline$R$ & 1.4 & 1.4 & 1.3 & 1.3 & 1.4 & 1.3 & 1.2 & 1.1 & 1.4 & 1.5 & 1.5 & 1.5 \\
\hline$E$ & 1.2 & 1.2 & 1.1 & 1.1 & 1.7 & 1.7 & 1.5 & 1.5 & 0.7 & 0.7 & 0.7 & 0.7 \\
\hline Glacier melt & 0.0 & 0.0 & 0.0 & 0.0 & 0.0 & 0.1 & 0.0 & 0.1 & 0.0 & 0.0 & 0.0 & 0.0 \\
\hline$\Delta S$ & 0.0 & -0.0 & 0.0 & -0.0 & -0.3 & -0.2 & -0.4 & -0.2 & 0.3 & 0.2 & 0.4 & 0.2 \\
\hline$\Delta \mathrm{SWE}$ & 0.0 & -0.0 & 0.0 & -0.0 & -0.2 & -0.1 & -0.2 & -0.1 & 0.2 & 0.1 & 0.2 & 0.1 \\
\hline$\Delta \mathrm{SM}$ & -0.0 & -0.0 & -0.0 & -0.0 & 0.0 & 0.0 & -0.0 & -0.0 & -0.0 & -0.0 & 0.0 & 0.0 \\
\hline \multicolumn{13}{|c|}{ Cologne } \\
\hline$P$ & 2.5 & 2.5 & 2.4 & 2.4 & 2.6 & 2.6 & 2.2 & 2.2 & 2.4 & 2.4 & 2.5 & 2.5 \\
\hline$R$ & 1.3 & 1.3 & 1.3 & 1.3 & 1.1 & 1.1 & 1.0 & 0.9 & 1.5 & 1.5 & 1.5 & 1.6 \\
\hline$E$ & 1.2 & 1.2 & 1.1 & 1.1 & 1.7 & 1.7 & 1.5 & 1.5 & 0.7 & 0.8 & 0.7 & 0.7 \\
\hline Glacier melt & 0.0 & 0.0 & 0.0 & 0.0 & 0.0 & 0.1 & 0.0 & 0.1 & 0.0 & 0.0 & 0.0 & 0.0 \\
\hline$\Delta S$ & -0.0 & -0.0 & -0.0 & -0.0 & -0.2 & -0.1 & -0.3 & -0.2 & 0.2 & 0.1 & 0.3 & 0.2 \\
\hline$\Delta \mathrm{SWE}$ & 0.0 & -0.0 & 0.0 & -0.0 & -0.1 & -0.1 & -0.1 & -0.1 & 0.1 & 0.1 & 0.1 & 0.1 \\
\hline$\Delta \mathrm{SM}$ & -0.0 & -0.0 & -0.0 & -0.0 & 0.0 & 0.0 & -0.0 & -0.0 & -0.0 & -0.0 & 0.0 & 0.0 \\
\hline
\end{tabular}

This is in line with the results by Steger et al. (2013), who looked at GCM-RCM snow data for a similar set of GCM-RCMs and found snowfall to decrease in general, with the exception of a few GCM-RCMs at elevations above $2000 \mathrm{~m}$ MSL.

The $T$ - and $P$-effect results are of significance in terms of uncertainty assessment. It is suggested that projected temperature changes, which are considered more reliable than projected precipitation changes, explain a substantial fraction of the response in the seasonality of runoff along the Rhine River.

\section{Summary and conclusions}

The present study assesses the impact of climate change on the hydrology of the Rhine River down to
Cologne using GCM-RCM model chains from the ENSEMBLES project. The methodology involves using the delta change postprocessing method and the hydrological model PREVAH. We found a robust decrease of mean runoff in summer and an increase in winter. This result is consistent with previous studies. The magnitude of changes in mean runoff considerably depends on the GCM-RCM. For Cologne and winter in the SCE period 2070-99, estimated maximal increases of mean runoff estimated by a 31-day MA range between $+4 \%$ and $+51 \%$. Also, the length of the period in the annual cycle during which runoff is projected to increase, varies considerably depending on the GCM$\mathrm{RCM}$ considered. It varies between periods as short as about 2 months in winter up to about 9 months from the beginning of autumn to the beginning of summer. Using 

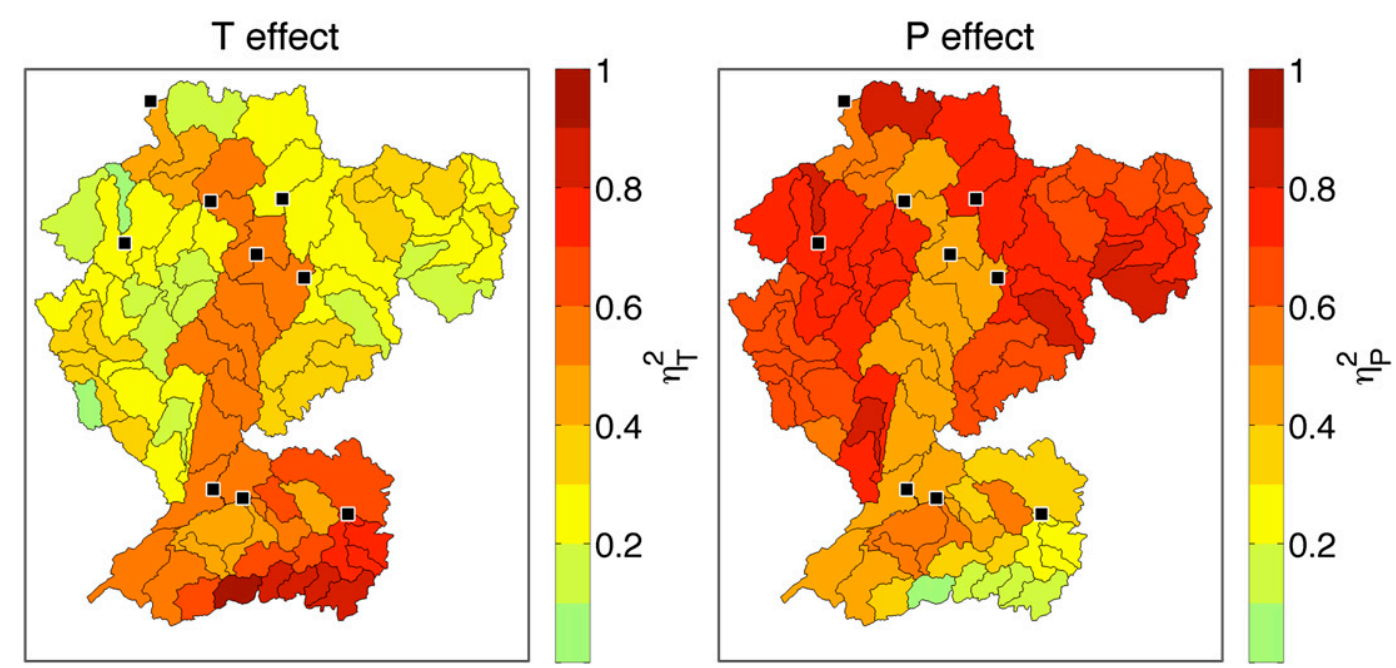

FIG. 10. Contributions of the (left) $T$ effect and (right) $P$ effect to changes of the annual cycle of the mean routed runoff. The coefficient $\eta^{2}$ measures how much of the projected changes are explained by a single effect $(T$ or $P)$. A value of 1 corresponds to $100 \%$ of explained variance. See Fig. 1 for geographical details of the catchment. The black squares denote the runoff gauging stations as in Fig. 1.

10 RCMs driven by one GCM from the PRUDENCE project, Graham et al. (2007) found increases in mean monthly runoff only between January and May and maximal increases in the range of $+5 \%-20 \%$, with one outlier projecting $+40 \%$. The smaller spread could be related to the fact that all GCM-RCM modeling chains used by Graham et al. (2007) are driven by one single GCM.

Our results clearly demonstrate that the driving GCM has a strong influence on the runoff scenarios. The HadCM3Q0-driven chains, for instance, show smaller runoff increases during a shorter period of the year than the ECHAM5-driven scenarios. Also regarding extreme runoff indices, the driving GCM strongly characterizes the estimated changes. This result highlights the importance of a multi-GCM ensemble for climate-runoff impact studies. To some extent, this result is related to the fact that temperature changes provide a substantial influence upon runoff changes, at least for the Alpine Rhine (see section 4e). For temperature changes, Déqué et al. (2005) found that the dominant uncertainty lies in the large-scale atmospheric circulation provided by the GCM. Nevertheless, differences between different RCMs (driven by the same GCM) are substantial and may strongly affect the total uncertainty.

Regarding the high-flow index MHQ, our results show stronger increases than the scenarios compiled within the Rheinblick2050 project (Görgen et al. 2010). For low-flow indices, our results show a clearer tendency toward a decrease than the more extensive scenario ensemble of the Rheinblick 2050 project. Because of the common GCM-RCM basis, these differences have to be caused by the different statistical postprocessing method (for this study, delta change; for Rheinblick2050, linear and nonlinear bias correction), the different CTL period (for this study, 1979-2008; for Rheinblick2050, 196190), or the different hydrological model. Previous work has found smaller increases in high-flow extremes when using postprocessing methods that account for variability changes, compared to using methods that ignore changes in the variability (Shabalova et al. 2003; Lenderink et al. 2007; Bosshard et al. 2013). Furthermore, the period 1979-2008 contains the most recent extreme floods in the years 1993 and 1995 (Disse and Engel 2001), which, in combination with a delta change scaling, likely leads to larger increases in the MHQ than in case of a CTL with fewer and smaller floods. Thus, our results regarding the runoff extreme indices have to be interpreted with caution and probably overestimate the changes of runoff extremes.

We also quantified the respective contribution of the temperature and precipitation changes to the projected changes in the mean annual cycle of runoff. Consistent with previous studies, we found that for the Alpine basins, the effect of temperature changes ( $T$ effect) determines the changes in the annual cycle of mean runoff to a large extent. In the major tributaries, however, it is the effect of precipitation changes $(P$ effect) that is more important. Thus, the dominance of the $T$ effect propagates downstream along the Upper and Middle Rhine but is diminished at the confluences of the tributaries with the Rhine. At Cologne, the $P$ effect is more important than the $T$ effect. In winter, however, the projected increase in runoff is caused by $T$ and $P$, with equal contributions of about $50 \%$ each. 
This study uses climate model data from the ENSEMBLES project, one postprocessing method, and one hydrological model. It extends the database of previous studies, which is partly compiled within the Rheinblick 2050 project. The general pattern of changes agrees among all studies, but the range of uncertainties documented here is larger. It requires further concerted research to include even more uncertainty sources in hydrological climate-impact studies (see, e.g., Wilby and Harris 2006; Bosshard et al. 2013) and to transfer the results into adaptation measures (Pelt and Swart 2011).

Acknowledgments. We would like to acknowledge all persons and institutions that provided data for our study. Regarding meteorological data, these were Olga Zolina (University of Bonn, Germany) and Hermann Mächel (German Weather Service); the German Weather Service; MeteoSwiss; MétéoFrance; the Federal Ministry of Agriculture, Forestry, Environment and Water Management (Austria); and the European Climate Assessment \& Dataset Project (Luxembourg). Regarding runoff data, these were (for Germany) the Federal Institute of Hydrology; Wasser- und Schifffahrtsverwaltung des Bundes; Landesanstalt fr Umwelt, Messungen und Naturschutz Baden-Württemberg; Bayerisches Landesamt für Umwelt; Ministerium für Umwelt, Landwirtschaft, Ernährung, Weinbau und Forsten Rheinland-Pfalz; Hessisches Landesamt für Umwelt und Geologie; and Landesamt für Umwelt- und Arbeitsschutz Saarland; (for France) DREAL Lorraine, $\mathrm{MEDD} / \mathrm{DE}$ and DREAL Alsace, MEDD/DE; and (for Switzerland) the Federal Office for the Environment. The climate model data was provided by the ENSEMBLES project, which was funded by the EU FP6 Integrated Project ENSEMBLES (Contract 505539) and whose support is gratefully acknowledged. Regarding spatial data, we thank the Commission for the Hydrology of the Rhine Basin (CHR) and the European Soil Database (ESDB). We are very grateful for the advice and help of Dr. Peter Krahe, Maria Carambia, and Eric Sprokkereef. The Center for Climate Systems Modeling (C2SM) at ETH Zurich is acknowledged for providing technical and scientific support.

\section{REFERENCES}

Allen, M. R., and W. J. Ingram, 2002: Constraints on future changes in climate and the hydrologic cycle. Nature, 419, 224-232, doi:10.1038/nature01092.

Arnell, N. W., 1992: Factors controlling the effects of climate change on river flow regimes in a humid temperate environment. J. Hydrol., 132, 321-342, doi:10.1016/0022-1694(92) 90184-W.

Barnett, T. P., J. C. Adam, and D. P. Lettenmaier, 2005: Potential impacts of a warming climate on water availability in snow-dominated regions. Nature, 438, 303-309, doi:10.1038/ nature 04141.

Belz, J. U., and Coauthors, 2007: Das Abflussregime des Rheins und seiner Nebenflüsse im 20. Jahrhundert (The runoff regime of the river Rhine and its tributaries in the 20th century). Rep. I-22, International Commission of the Hydrology of the Rhine Basin, 377 pp. [Available online at http://www.chr-khr.org/ files/RapportI-22.pdf.]

Bosshard, T., S. Kotlarski, T. Ewen, and C. Schär, 2011: Spectral representation of the annual cycle in the climate change signal. Hydrol. Earth Syst. Sci., 15, 2777-2788, doi:10.5194/ hess-15-2777-2011.

_-, M. Carambia, K. Goergen, S. Kotlarski, P. Krahe, M. Zappa, and C. Schär, 2013: Quantifying uncertainty sources in an ensemble of hydrological climate-impact projections. Water Resour. Res., 49, 1523-1536, doi:10.1029/2011WR011533.

Christensen, J. H., T. R. Carter, M. Rummukainen, and G. Amanatidis, 2007: Evaluating the performance and utility of regional climate models: The PRUDENCE project. Climatic Change, 81, 1-6, doi:10.1007/s10584-006-9211-6.

CHR/KHR, 1978: Das Rheingebiet, Hydrologische Monographie (The Rhine river, hydrological monograph). KHR Rep., Internationale Kommission für die Hydrologie des Rheingebietes, $564 \mathrm{pp}$.

Déqué, M., and Coauthors, 2005: Global high resolution versus Limited Area Model climate change projections over Europe: Quantifying confidence level from PRUDENCE results. Climate Dyn., 25, 653-670, doi:10.1007/s00382-005-0052-1.

- S. Somot, E. Sanchez-Gomez, C. M. Goodess, D. Jacob, G. Lenderink, and O. B. Christensen, 2012: The spread amongst ensembles regional scenarios: Regional climate models, driving general circulation models and interannual variability. Climate Dyn., 38, 951-964, doi:10.1007/ s00382-011-1053-x.

Disse, M., and H. Engel, 2001: Flood events in the Rhine basin: Genesis influences and mitigation. Nat. Hazards, 23, 271-290, doi:10.1023/A:1011142402374.

Doherty, J., L. Brebber, and P. Whyte, 2005: PEST: ModelIndependent Parameter Estimation. 5th ed. User manual, Watermark Numerical Computing, 336 pp. [Available online at http://www.pesthomepage.org/getfiles.php?file=pestman. pdf.]

Gleick, P. H., 1986: Methods for evaluating the regional hydrologic impacts of global climatic changes. J. Hydrol., 88, 97-116, doi:10.1016/0022-1694(86)90199-X.

Görgen, K., and Coauthors, 2010: Assessment of climate change impacts on discharge in the Rhine River basin: Results of the Rheinblick2050 project. KHR Rep. I-23, 229 pp. [Available online at http://www.chr-khr.org/files/CHR_I-23.pdf.]

Graham, L. P., S. Hagemann, S. Jaun, and M. Beniston, 2007: On interpreting hydrological change from regional climate models. Climatic Change, 81, 97-122, doi:10.1007/s10584-0069217-0.

Gurtz, J., A. Baltenswiler, and H. Lang, 1999: Spatially distributed hydrotope-based modelling of evapotranspiration and runoff in mountainous basins. Hydrol. Processes, 13, $2751-$ 2768, doi:10.1002/(SICI)1099-1085(19991215)13:17<2751: AID-HYP897>3.0.CO;2-O.

Haylock, M. R., N. Hofstra, A. M. G. Klein Tank, E. J. Klok, P. D. Jones, and M. New, 2008: A European daily high-resolution gridded data set of surface temperature and precipitation for 1950-2006. J. Geophys. Res., 113, D20119, doi:10.1029/ 2008JD010201. 
Hurkmans, R., W. Terink, R. Uijlenhoet, P. Torfs, D. Jacob, and P. A. Troch, 2010: Changes in streamflow dynamics in the Rhine basin under three high-resolution regional climate scenarios. J. Climate, 23, 679-699, doi:10.1175/2009JCLI3066.1.

Jaun, S., B. Ahrens, A. Walser, T. Ewen, and C. Schär, 2008: A probabilistic view on the August 2005 floods in the Upper Rhine catchment. Nat. Hazards Earth Syst. Sci., 8, 281-291, doi:10.5194/nhess-8-281-2008.

King, D., J. Daroussin, and R. Tavernier, 1994: Development of a soil geographic database from the soil map of the European communities. Catena, 21, 37-56, doi:10.1016/0341-8162(94)90030-2.

Kleinn, J., C. Frei, J. Gurtz, D. Lüthi, P. L. Vidale, and C. Schär 2005: Hydrologic simulations in the Rhine basin driven by a regional climate model. J. Geophys. Res., 110, D04102, doi:10.1029/2004JD005143.

Kotlarski, S., T. Bosshard, D. Lüthi, P. Pall, and C. Schär, 2012: Elevation gradients of European climate change in the regional climate model COSMO-CLM. Climatic Change, 112, 189-215, doi:10.1007/s10584-011-0195-5.

Kwadijk, J., and H. Middelkoop, 1994: Estimation of impact of climate change on the peak discharge probability of the river Rhine. Climatic Change, 27, 199-224, doi:10.1007/BF01093591.

Lenderink, G., A. Buishand, and W. van Deursen, 2007: Estimates of future discharges of the river Rhine using two scenario methodologies: Direct versus delta approach. Hydrol. Earth Syst. Sci., 11, 1145-1159, doi:10.5194/hess-11-1145-2007.

Meehl, G. A., and Coauthors, 2007: Global climate projections. Climate Change 2007: The Physical Science Basis, S. Solomon et al., Eds., Cambridge University Press, 747-845.

Menzel, L., A. H. Thieken, D. Schwandt, and G. Bürger, 2006: Impact of climate change on the regional hydrology-Scenariobased modelling studies in the German Rhine catchment. Nat. Hazards, 38, 45-61, doi:10.1007/s11069-005-8599-z.

Middelkoop, H., and Coauthors, 2001: Impact of climate change on hydrological regimes and water resources management in the Rhine basin. Climatic Change, 49, 105-128, doi:10.1023/ A:1010784727448.

Murphy, J. M., B. B. B. Booth, M. Collins, G. R. Harris, D. M. H. Sexton, and M. J. Webb, 2007: A methodology for probabilistic predictions of regional climate change from perturbed physics ensembles. Philos. Trans. Roy. Soc. London, A365, 1993-2028, doi:10.1098/rsta.2007.2077.

Nash, J. E., and J. V. Sutcliffe, 1970: River flow forecasting through conceptual models. Part I-A discussion of principles. J. Hydrol., 10, 282-290, doi:10.1016/0022-1694(70)90255-6.

Nijssen, B., G. M. O’Donnell, A. F. Hamlet, and D. P. Lettenmaier, 2001: Hydrologic sensitivities of global rivers to climate change. Climatic Change, 50, 143-175, doi:10.1023/A:1010616428763.

Pelt, S. C., and R. J. Swart, 2011: Climate change risk management in transnational river basins: The Rhine. Water Resour. Manage., 25, 3837-3861, doi:10.1007/s11269-011-9891-1.

Penman, H. L., 1956: Estimating evaporation. Trans. Amer. Geophys. Union, 37, 43-46.

Rotach, M. W., and Coauthors, 2009: MAP D-PHASE: Real-time demonstration of weather forecast quality in the Alpine region. Bull. Amer. Meteor. Soc., 90, 1321-1336, doi:10.1175/ 2009BAMS2776.1.

Schulla, J., 1997: Hydrologische Modellierung von Flussgebieten zur Abschätzung der Folgen von Klimaveränderungen (Hydrolgoical modeling of river basins for an assessment of impacts of climate change). Ph.D thesis, ETH Zurich, Zurich,
Switzerland, $163 \mathrm{pp}$. [Available online at http://www.wasim. ch/downloads/doku/wasim/schulla_1997.pdf.]

Shabalova, M. V., W. P. A. van Deursen, and T. A. Buishand, 2003: Assessing future discharge of the river Rhine using regional climate model integrations and a hydrological model. Climate Res., 23, 233-246, doi:10.3354/cr023233.

Steger, C., S. Kotlarski, T. Jonas, and C. Schär, 2013: Alpine snow cover in a changing climate: A regional climate model perspective. Climate Dyn., 41, 735-754, doi:10.1007/s00382-012-1545-3.

te Linde, A. H., J. C. J. H. Aerts, A. M. R. Bakker, and J. C. J. Kwadijk, 2010: Simulating low-probability peak discharges for the Rhine basin using resampled climate modeling data. Water Resour. Res., 46, W03512, doi:10.1029/2009WR007707.

van der Linden, P., and J. Mitchell, Eds., 2009: ENSEMBLES: Climate change and its impacts: Summary of research and results from the ENSEMBLES project. Met Office Rep., $160 \mathrm{pp}$. [Available online at http://ensembles-eu.metoffice. com/docs/Ensembles_final_report_Nov09.pdf.]

Verbunt, M., M. Zappa, J. Gurtz, and P. Kaufmann, 2006: Verification of a coupled hydrometeorological modelling approach for alpine tributaries in the Rhine basin. J. Hydrol., 324, 224238, doi:10.1016/j.jhydrol.2005.09.036.

—, A. Walser, J. Gurtz, A. Montani, and C. Schär, 2007: Probabilistic flood forecasting with a limited-area ensemble prediction system: Selected case studies. J. Hydrometeor., 8, 897-909, doi:10.1175/JHM594.1.

Viviroli, D., M. Zappa, J. Gurtz, and R. Weingartner, 2009: An introduction to the hydrological modelling system PREVAH and its pre- and post-processing-tools. Environ. Modell. Software, 24, 1209-1222, doi:10.1016/j.envsoft.2009.04.001.

von Storch, H., and F. W. Zwiers, 1999: Statistical Analysis in Climate Research. Cambridge University Press, 484 pp.

Wilby, R. L., and I. Harris, 2006: A framework for assessing uncertainties in climate change impacts: Low-flow scenarios for the River Thames, UK. Water Resour. Res., 42, W02419, doi:10.1029/2005WR004065.

Wild, M., J. Grieser, and C. Schär, 2008: Combined surface solar brightening and increasing greenhouse effect support recent intensification of the global land-based hydrological cycle. Geophys. Res. Lett., 35, L17706, doi:10.1029/2008GL034842.

Wösten, J. H., A. Lilly, A. Nemes, and C. Le Bas, 1999: Development and use of a database of hydraulic properties of European soils. Geoderma, 90, 169-185, doi:10.1016/ S0016-7061(98)00132-3.

Zappa, M., and J. Gurtz, 2003: Simulation of soil moisture and evapotranspiration in a soil profile during the 1999 MAPRiviera campaign. Hydrol. Earth Syst. Sci., 7, 903-919, doi:10.5194/hess-7-903-2003.

, F. Pos, U. Strasser, P. Warmerdam, and J. Gurtz, 2003: Seasonal water balance of an alpine catchment as evaluated by different methods for spatially distributed snowmelt modelling. Nord. Hydrol., 34, 179-202.

- S. Jaun, U. Germann, A. Walser, and F. Fundel, 2011: Superposition of three sources of uncertainties in operational flood forecasting chains. Atmos. Res., 100, 246-262, doi:10.1016/j.atmosres.2010.12.005.

Zolina, O., C. Simmer, A. Kapala, S. Bachner, S. Gulex, and H. Maechel, 2008: Seasonally dependent changes of precipitation extremes over Germany since 1950 from a very dense observational network. J. Geophys. Res., 113, D06110, doi:10.1029/2007JD008393. 